\title{
THE NYMPH OF \\ WILLIAMSONIA LINTNERI (HAGEN) \\ (ODONATA: CORDULIIDAE)
}

\section{By Harold B. White, III ${ }^{1}$ and Rudolf A. RafF ${ }^{2}$}

The genus Williamsonia (Davis 1913) is composed of two littleknown species: lintneri (Hagen 1878 ) and fetcheri (Williamson 1923). Both are rather similar with respect to their early flight season and their habitat preference. Williamsonia lintneri is recorded in the literature from only four northeastern states of the U.S.A.: Massachusetts, Rhode Island, New York, and New Jersey. Williamsonia fletcheri has a larger and more northern distribution which includes the states of Maine, Massachusetts, New York, and Michigan, and four provinces of Canada: Manitoba, New Brunswick, Ontario, and Quebec. Of Williamsonia lintneri, Howe (1923) commented:

"The dates, as will be seen, range from April 1 to June 4 (sic) and undoubtably the reason Williamsonia lintneri has been overlooked is because of its early flight season when collectors are not alive to the presence of Odonata in the field. ... I always find it a woodland species inhabiting the neighborhood of cold bogs and brook runs.... Its larva is unknown."

In his description of Williamsonia fetcheri, Williamson ( 1923) quoted similar comments from a letter of J. H. McDunnough, collector of the type specimens near Ottawa, Ontario.

" 'This species is one of the earliest to occur in our locality and nearly all the specimens I took were more or less teneral and were taken in a small spruce grove close to a sphagnum bog which contained several open pools of water, in which I presume the nymphs lived.'”

Both Howe and Williamson were interested in obtaining a nymph of Williamsonia but neither succeeded. In the ea:ly 1930's Dr. James G. Needham of Cornell University offered five dollars and a copy of his book (Needham and Heywood 1929) to anyone at Harvard University who could produce a nymph of Williamsonia. ${ }^{3}$ Apparently the prospect of wading in cold bogs in the early spring

\footnotetext{
${ }^{1}$ James Bryant Conant Laboratory, Harvard University, Cambridge, Massachusetts 02138 .

${ }^{2}$ Biology Department, Massachusetts Institute of Technology, Cambridge, Massachusetts 02139 .

${ }^{3}$ This story was related to us by Dr. Floyd Werner, University of Arizona, who was a graduate student at Harvard at the time of Dr. Needham's offer.
} 


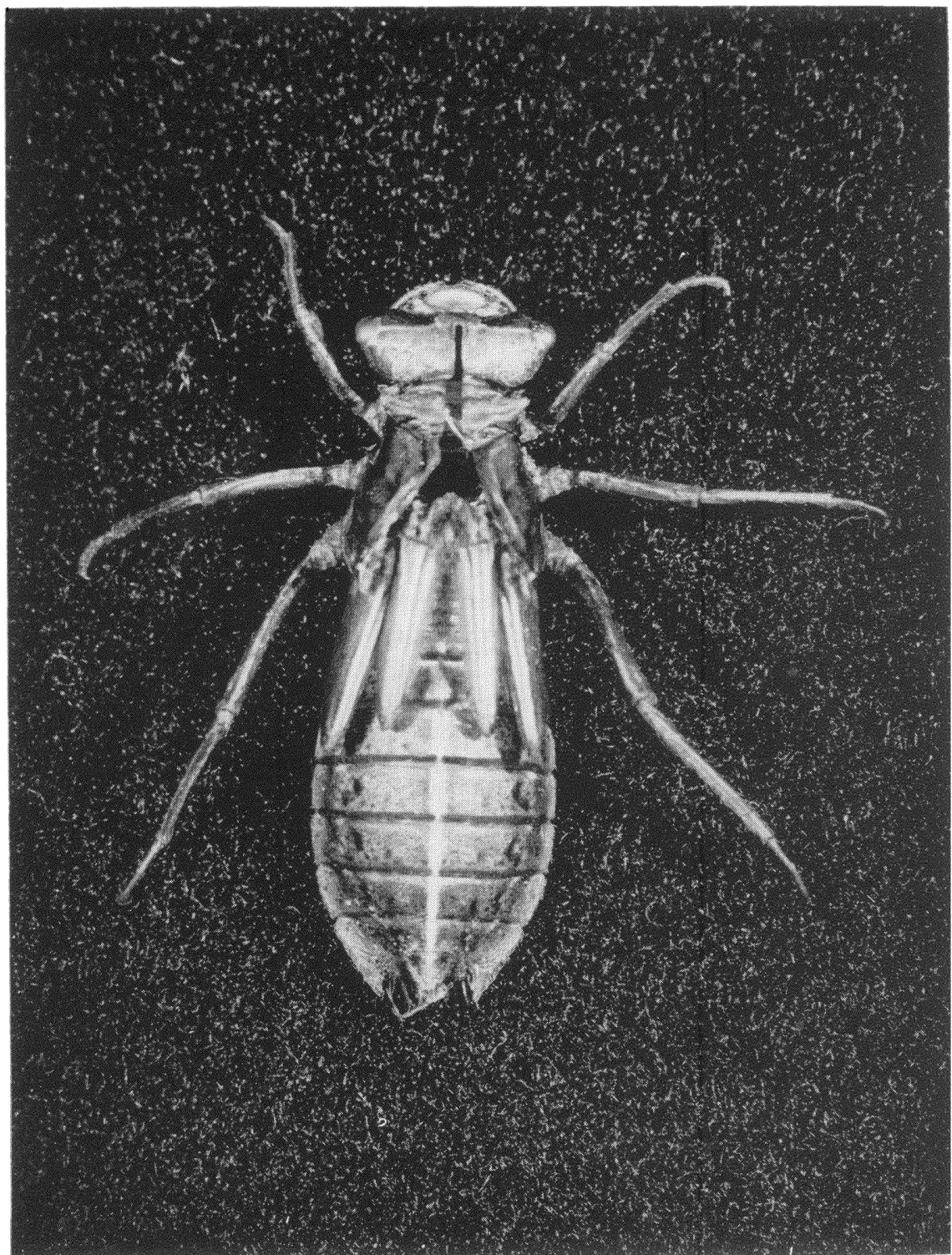

Figure 1. Dorsal view of an exuvia of Williamsonia lintneri, male. 
searching for an unknown nymph was not worth the reward even during the Depression, for the search was never made. Since that time few serious attempts to collect the nymph have been made. With the exception of a few predominantly tropical genera whose ranges extend into extreme southern United States or northern Mexico, Williamsonia is the last genus of Nearctic Odonata for which the nymph heretofore has been undescribed. ${ }^{4}$ In this paper we describe the nymph of Williamsonia lintneri.

During May for the past three years we have frequently collected adults of lintneri in the vicinity of a 40-hectare bog adjacent to Ponkapoag Pond in the Blue Hills of eastern Massachusetts $\left(42^{\circ}\right.$ I $\left.2^{\prime} \mathrm{N}, 7 \mathrm{I}^{\circ} \mathrm{06} 6^{\prime} \mathrm{W}\right)$. Our observations of the adults range from 30 April to 26 May. Although we rarely observed adults in the bog, their close association with the woodlands bordering the bog suggested that the bog, not the pond, was the habitat of the nymph. Dredging at several locations within the bog was unsuccessful; however, the flushing of a teneral adult from its site of emergence on 2 May 1970 led to the discovery of twelve exuviae and a full grown nymph which emerged three hours after its capture. The exuviae were shown to be lintneri by comparison to the exuvia of the reared nymph.

The nymph and exuviae were collected adjacent to a log path where it crosses an overgrown channel $275 \mathrm{~m}$ from the bog margin. Here, in contrast to most other parts of the bog, the water is deep and remains year-around despite fluctuations created by summertime irrigation of a nearby golf course. Highbush blueberry (Vaccinium corymbosum), swamp laurel (Kalmia polifolia), leather leaf (Chamaedaphne calyculata), and Atlantic Coast White Cedar (Chamaecyparis thyoides) form dense thickets on both sides of the channel while the channel itself is choked with sphagnum, water arum (Calla palustris), and other water plants.

All of the exuviae of Williamsonia lintneri were found within I $5 \mathrm{~cm}$ of the water surface on emergent vegetation. Over half (7) of the exuviae were clustered within a two square meter area where young shoots of marsh grass were particularly dense. The teneral adults observed in the bog and the emergence of the reared nymph suggest that emergence takes place about midday. The fact tha: all but three of the exuviae collected in the area mentioned above were collected on or before 3 May indicates that the peak emergence

${ }^{4}$ Dr. Minter J. Westfall, Jr., personal communication. 
period was over by that time. On 3 May the surface water temperature was $15^{\circ} ; 60 \mathrm{~cm}$ below the surface the temperature was $10^{\circ}$. In association with lintneri were nymphs of Libellula quadrimaculata L., Sympetrum rubicundulum (Say), and Chromagrion conditum (Hagen). In addition an exuvia of Leucorrhinia hudsonica (Selys) was found in the same area. Later in the year this portion of the bog is inhabited by the above species as well as Gomphaeschna furcillata (Say), Nannothemis bella (Uhler), Leucorrhinia proxima Calvert, and a large population of Nehalennia gracilis Morse.

\section{Williamsonia lintneri (Hagen)}

Specimens examined - An exuvia from a nymph which emerged in captivity and twelve exuviae collected 2 May-9 May I970 at Ponkapoag Bog, Blue Hills Reservation, Norfolk County, Massachusetts. ${ }^{5}$

Description - Body length I7-I $8 \mathrm{~mm}$, width of the abdomen 7.5 $\mathrm{mm}$. In general appearance the nymph is light brown in color and practically devoid of prominent setae except on the hind margin of abdominal segment 9 and on the hind tibiae. The dorsum of the abdomen is speckled with small spots of darker pigmentation and a narrow stripe of lighter pigmentation extends down the dorsal ridge (Figure I). The wing sheaths extend to the base or middle of abdominal segment 6 . Dorsal spines are present on abdominal segments 3 through 9. In profile (Figure 2) they are rather small and project posteriorly. Lateral spines are present only on abdominal segment 9 where they form about one-third of the lateral margin of that segment. Setae along the posterior margin of segment 9 are about twice as long as the lateral spines.

There are seven antennal segments. There are no dorsal horns on the head. The labium is as shown in Figure 3. Premental setae (terminology of Corbet I95.3) usually number I2 $+\mathrm{I} 2$ but a range from II $+I_{I}$ to $I 2+{ }_{1} I 2$ was observed. The even spacing of the 8 palpal setae on each palpus is interrupted slightly between

\footnotetext{
"Of these specimens seven have been distributed to the following institutions and investigators: Florida State Collection of Arthropods, Gainesville, c/o Dr. Minter J. Westfall, Jr.; Royal Ontario Museum, Toronto and The Canadian National Collection, Ottawa, c/o Dr. Philip S. Corbet; The U. S. National Museum, Washington, D. C., c/o Dr. Oliver S. Flint, Jr.; The University of Michigan Museum of Zoology, Ann Arbor, c/o Mrs. Leonora K. Gloyd; G. H. and A. F. Beatty, State College, Pennsylvania; and the Museum of Comparative Zoology, Harvard University, c/o Dr. Howard Evans.
} 

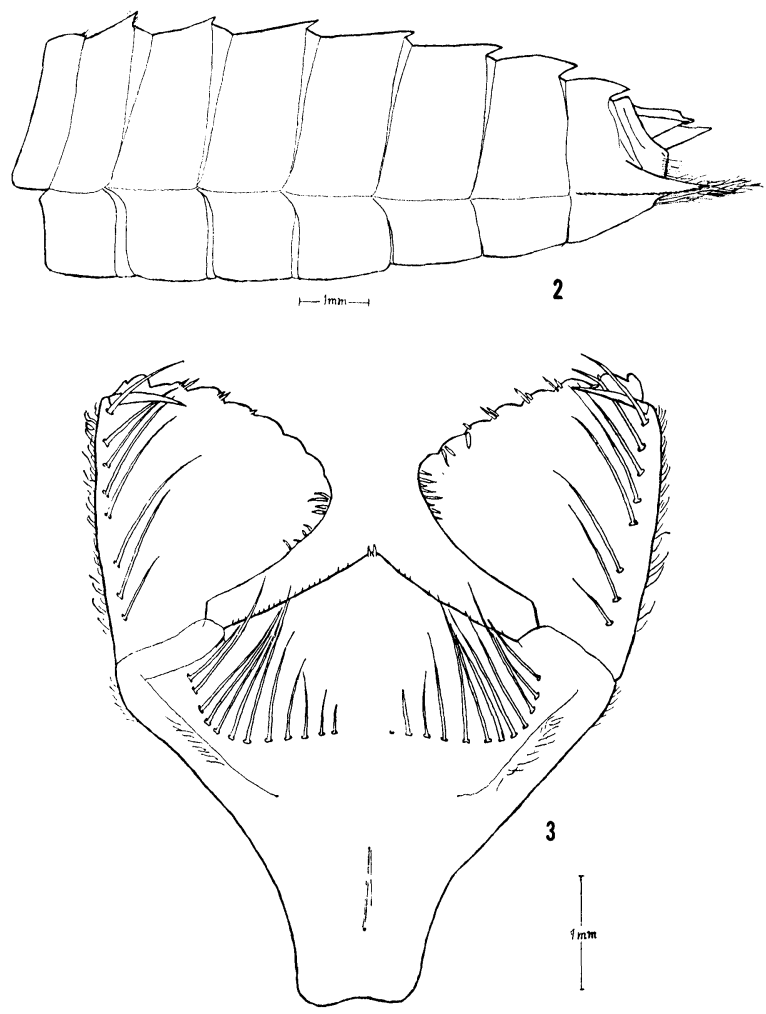

Figure 2. Lateral view of an exuvia of Williamsonia lintneri, male, showing dorsal spines on abdominal segments 3 through 9 and the conspicuous setae on segment 9.

Figure 3. Labium of the nymph of Williamsonia linteri.

the third and fourth setae from the proximal end. The distal margin of the palpus possesses seven or eight crenulations which become progressively deeper near the movable hook. Each crenulation except that nearest the movable hook usually bears two spiniform setae of unequal length. The inner margin of the palpus near the apex has about ten irregularly placed spiniform setae, which are directed inward. The legs are uniform in color with relatively few setae except on the middle and hind tibiae. The setae on the hind tibiae are arranged in two rows with the posterior one being more prominent. 
Discussion - When Davis (1913) erected the genus Williamsonia, he noted the difficulties previous investigators had had in assigning Williamsonia lintneri to the already established genera. Certain characters of wing venation in particular were quite distinct while others suggested affinity with the Libellulidae. The nymph of Williamsonia lintneri also differs from those of other corduliid genera and consequently gets lost in the keys of Needham and Westfall (1955, p. 349) and of Gloyd and Wright (1959). In general appearance the nymph of Williamsonia lintneri somewhat resembles that of Dorocordulia lepida (Hagen); however, it is easily distinguished from that species and the nymphs of all other corduliid genera by the combined presence of dorsal hooks on abdominal segments 3 through 9 and lateral spines on abdominal segment 9 only.

\section{Acknowledgements}

We especially thank Dr. Philip S. Corbet and Dr. Minter J. Westfall, Jr. for reading the first draft of this manuscript and making numerous helpful suggestions. We also thank Dr. Frank M. Carpenter for his encouragement and editorial comments.

\section{REFERENCES}

Corbet, Philip S.

1953. A terminology for the labium of larval Odonata. The Entomologist 86: 191-196.

D.AvIs, WM. T.

1913. Williamsonia, a new genus of dragonflies from North America. Bull. Brooklyn Ent. Soc. 8: 93-96.

Gloyd, LeONORA $\mathrm{K}$. and Mike Wright

1959. Chapter 34 in Ward and Whipple, Fresh Water Biology, W. T. Edmondson (Ed.), John Wiley and Sons, Inc. New York, N.Y.

Hagen, Herman A.

1878. Cordulia lintneri, In Selys, Secondes additions au Synopsis des Cordulines. Bull Acad. Belg. 45: 187-188.

Howe, R. Heber

1923. Williamsonia lintneri (Hagen), its history and distribution. Psyche 30:222-225.

Needham, James G. and Hortense B. Heywood

1929. A Handbook of the Dragonflies of North America, 378 pp. Chas. C. Thomas, Springfield, Ill., and Baltimore, Md.

Needham, James G. and Minter J. Westfall, JR.

1955. A Manual of the Dragonfies of North America, 615 pp. University of California Press, Berkeley and Los Angeles.

Williamson, E. B.

1923. A new species of Williamsonia (Odonata-Corduliinae). Can. Ent. 55: 96-98. 

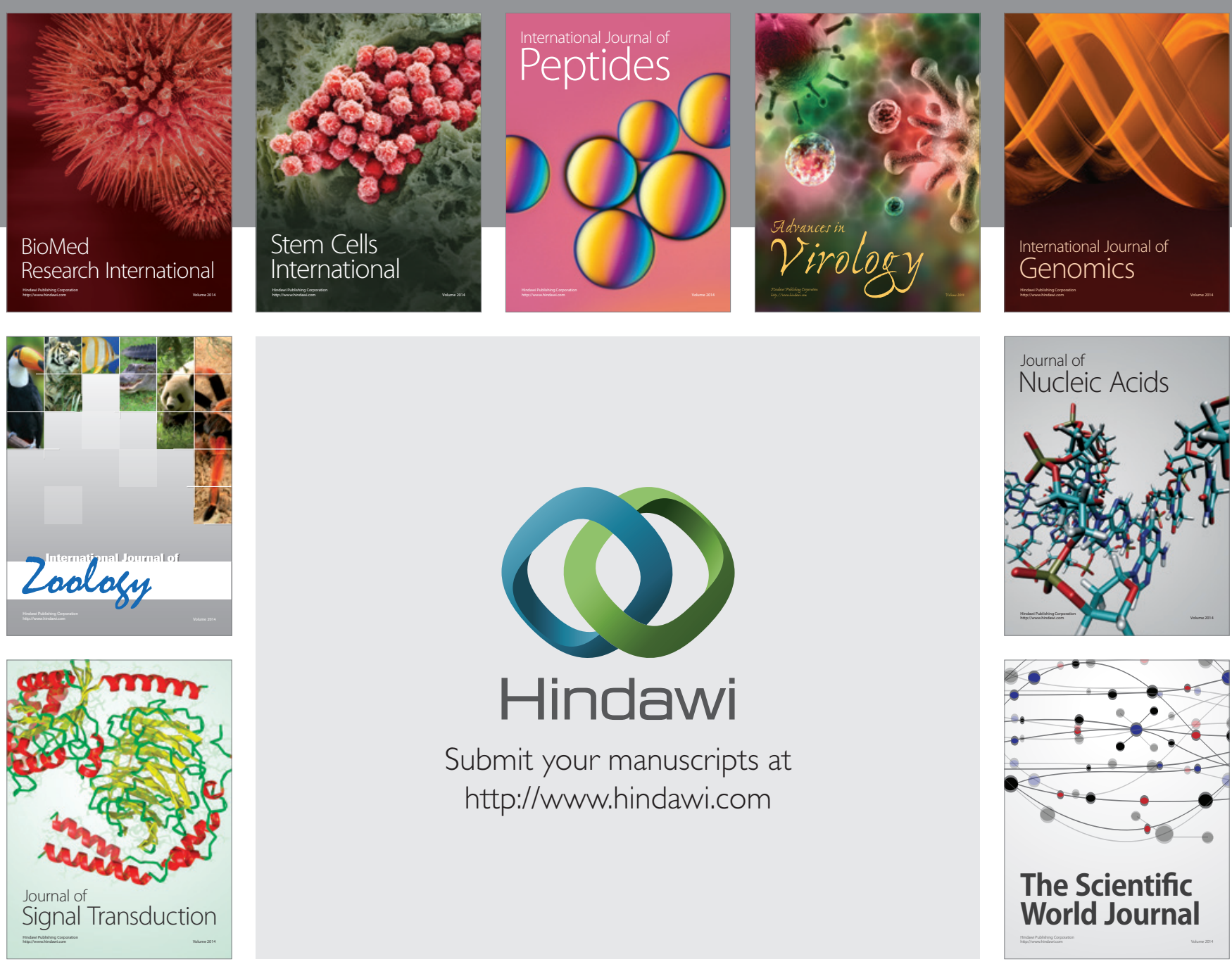

Submit your manuscripts at

http://www.hindawi.com
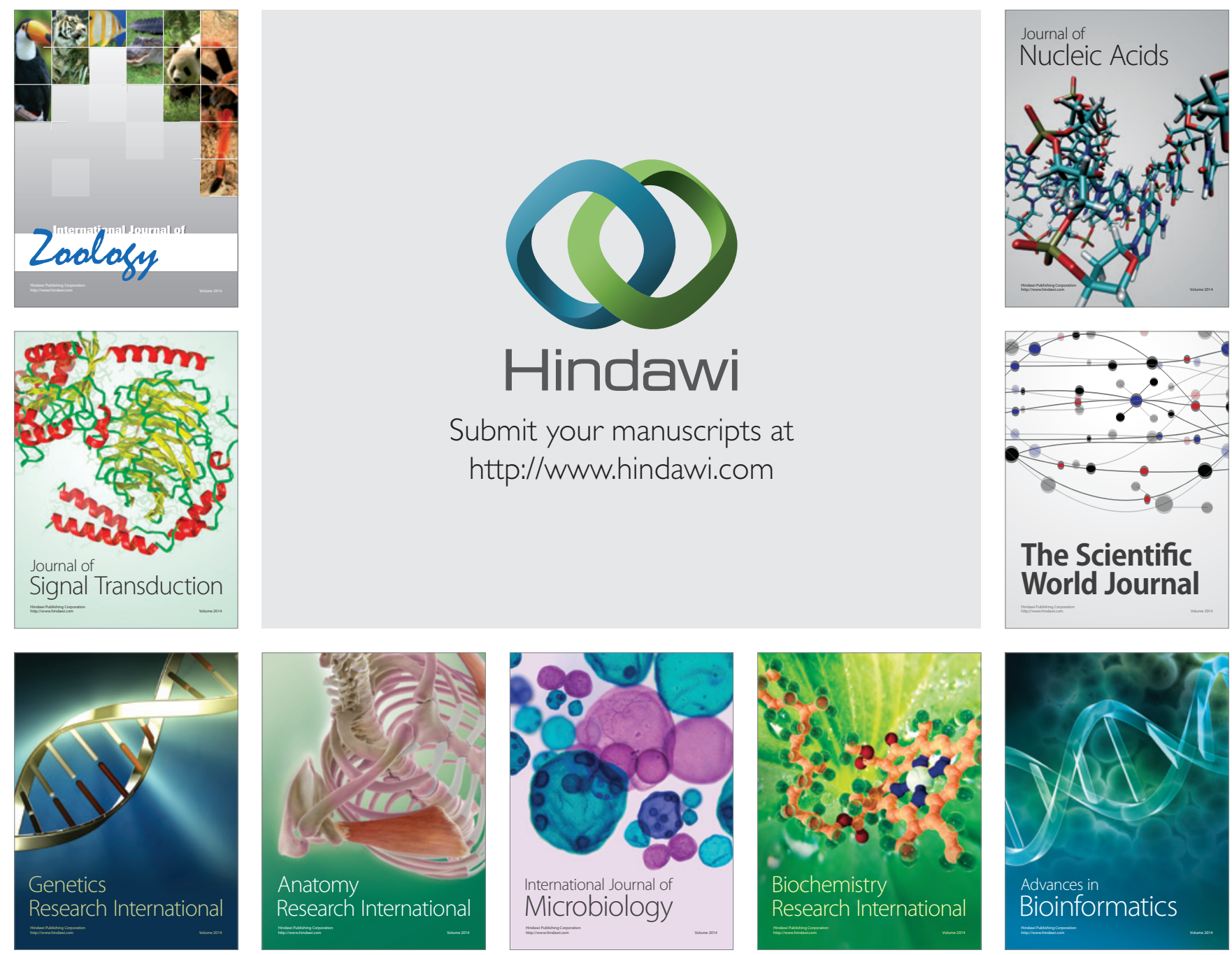

The Scientific World Journal
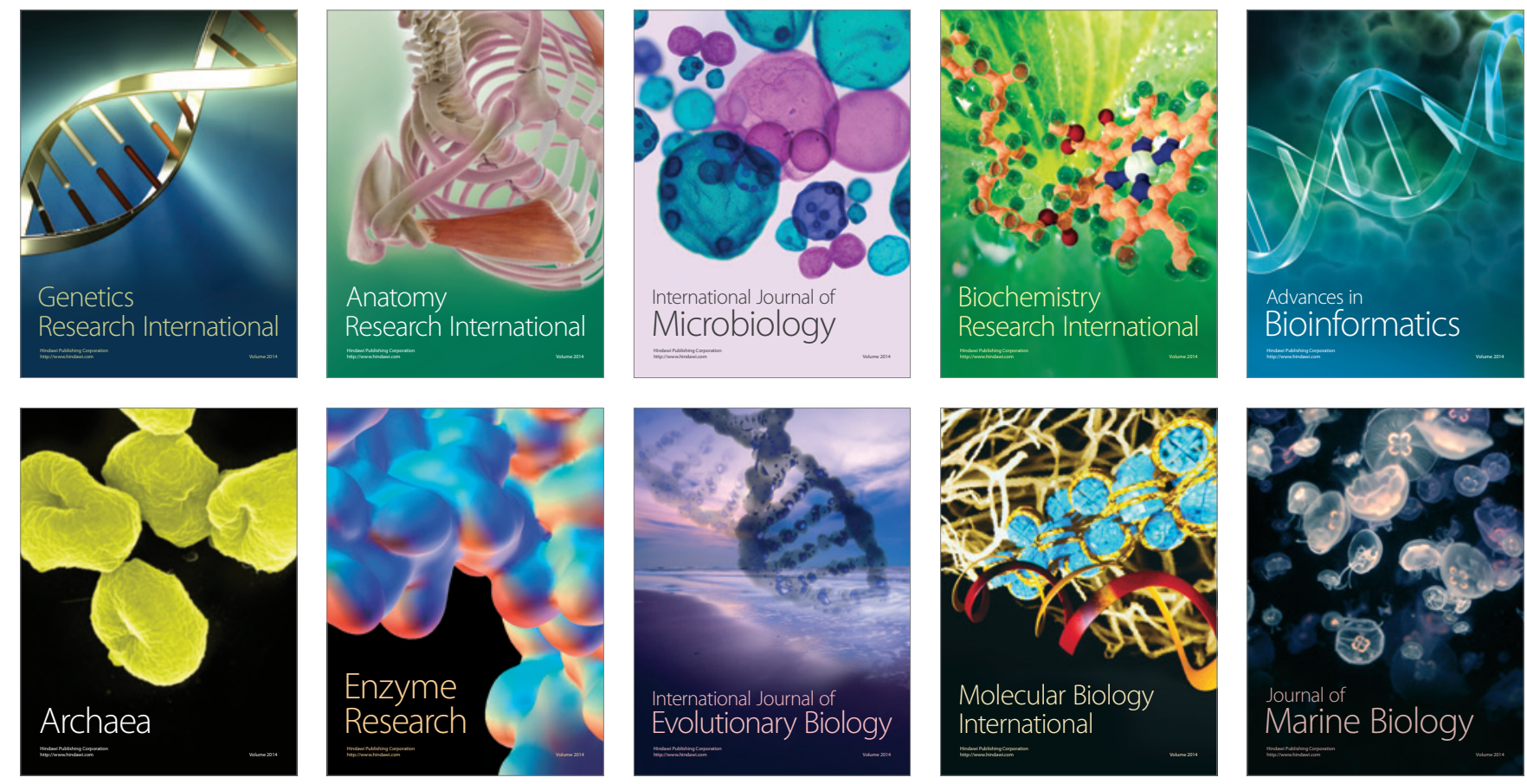